\title{
Vascular regrowth following photodynamic therapy in the chicken embryo chorioallantoic membrane
}

\author{
Patrycja Nowak-Sliwinska · Judy R. van Beijnum • \\ Maaike van Berkel · Hubert van den Bergh • \\ Arjan W. Griffioen
}

Received: 24 June 2010/Accepted: 30 August 2010/Published online: 15 September 2010

(C) The Author(s) 2010. This article is published with open access at Springerlink.com

\begin{abstract}
Photodynamic therapy (PDT) induces damage to the endothelium, which can lead to increased vascular permeability and, under intensive PDT conditions, even to platelet aggregation, vasoconstriction, and blood flow stasis. Eventually, ischemia, hypoxia, and inflammation can occur, resulting in angiogenesis. We studied the sequence of the vascular events after Visudyne ${ }^{\circledR}$-PDT in the chicken chorioallantoic membrane (CAM) at day 11 of development. Using epi-fluorescence microscopy, we monitored the regrowth of capillaries in the PDT treated area. Immediately after irradiation, the treatment resulted in blood flow arrest. And $24 \mathrm{~h}$ post PDT, sprouting of new blood vessels was observed at the edge of the PDT zone. Neovessels looping out from the edge of the PDT zone gave rise to specialized endothelial tip structures guiding the vessels towards the center of the treated area. At $48 \mathrm{~h}$ almost all of the treated area was repopulated with functional but morphologically altered vasculature. These observations also showed reperfusion of some of the vessels that had been closed by the PDT treatment. CAM samples were immunohistochemically stained for Ki-67 showing proliferation of endothelial cells in the PDT area. Also, several markers of immature and angiogenic blood vessels, such as $\alpha \mathrm{V} \beta 3$ integrin, vimentin and galectin-1, were found to be enhanced in the PDT area, while the endothelial maturation marker intercellular adhesion molecule (ICAM)-1 was
\end{abstract}

P. Nowak-Sliwinska $(\bowtie) \cdot$ H. van den Bergh

Medical Photonics Group, Institute of Bioengineering,

Swiss Federal Institute of Technology (EPFL), Station 6,

1015 Lausanne, Switzerland

e-mail: Patrycja.Nowak-Sliwinska@epfl.ch

J. R. van Beijnum · M. van Berkel · A. W. Griffioen Department of Medical Oncology, Angiogenesis Laboratory, VU University Medical Center, Amsterdam, The Netherlands found to be suppressed. These results demonstrate that the new vascular bed is formed by both neo-angiogenesis and reperfusion of existing vessels. Both the quantitative realtime RT-PCR profile and the response to pharmacological treatment with $\operatorname{Avastin}^{\circledR}$, an inhibitor of angiogenesis, suggest that angiogenesis occurs after PDT. The observed molecular profiling results and the kinetics of gene regulation may enable optimizing combination therapies involving PDT for treatment of cancer and other diseases.

Keywords Photodynamic therapy - Capillary - VEGF . Angiogenesis · Real-time RT-PCR · Visudyne ${ }^{\circledR}$.

Avastin $^{\circledR} \cdot$ Galectin-1 · Vimentin

\section{Introduction}

Photodynamic therapy (PDT) is a minimally invasive treatment modality that can potentially destroy unwanted neoplastic tissue [1] while sparing neighbouring normal tissue. PDT involves site-specific activation of an administered photosensitizer using light of an appropriate wavelength, in order to generate cytotoxic reactive oxygen species that induce cellular and/or vascular damage, as well as inflammatory and angiogenic responses [2-4]. In the vasculature PDT can lead to cytoskeleton damage in the endothelium and endothelial cell retraction causing increased space between these cells. This can lead, when applied in patients, to exposure of the vascular basement membrane and the release of Von Willebrand factor, and, as a consequence to platelet activation and aggregation [2]. The effects of PDT in blood vessels, such as vessel constriction and stasis of flow shortly after phototherapy have been described by Star et al. [5] They speculated that vascular damage plays an important role in tumor cure next to the direct effects of PDT on tumor 
cells. These findings are supported by the report of Henderson et al. [6] who quantified tumor cell clonogenicity at various times after PDT and found that the viability of tumor cells was nearly unaffected by PDT. Also, Selman et al. [7] demonstrated reductions in blood flow after phototherapy using a radioactive microsphere method. Reed et al. [8] studied vessel constriction using an intravital microscopy model and reported similar results. These studies identified platelet aggregation and vessel constriction as early events in PDT.

The angio-occlusive effect of PDT is currently used to treat non-cancerous vascular diseases. Prominent in this regard is the worldwide approval (in over 70 countries, including the USA) of verteporfin (Visudyne ${ }^{\circledR}$ )-based PDT for the treatment of exudative age-related macular degeneration (AMD), as well as for subfoveal choroidal neovascularization (CNV) due to pathologic myopia and ocular histoplasmosis syndrome [9]. A wide range of other diseases is under investigation for treatment with PDT using verteporfin or other PDT agents, including rheumatoid arthritis [10] and different forms of cancer [11, 12].

A suitable model for studying vascular effects of PDT is the well-vascularized chorioallantoic membrane (CAM) of the chicken embryo (Gallus gallus). This model has several advantages over other animal models, including the fact that the CAM consists of a thin, planar vascular network, which is well adapted to observation by microscopy [13] Furthermore, the CAM provides an easily accessible neovascular network in a transparent matrix. It allows direct visualization of blood vessels before, during and after PDT, and during pharmacological intervention. The CAM has been successfully used to evaluate the photodynamicallyinduced vascular occlusion efficacy of some PDT photosensitizers, that are in clinical trials or are already FDA approved [14-17]. The CAM model has also been extensively used in angiogenesis research [18-20].

Research on the effect of PDT on the vasculature demonstrated that this treatment often results in the induction of angiogenesis, which is the major rationale for combining PDT with anti-angiogenesis therapy. The relationship between PDT and angiogenesis was first described by Ferrario et al. [21], who demonstrated that the effectiveness of PDT may be enhanced by combination with angiogenesis inhibitors, an approach that we also recently validated [14, 22]. In general, it was assumed that the PDT induced changes in the tissue result in the formation of new vasculature. This assumption was mainly based on the observation of the changed and tortuous appearance of the vasculature [14, 23, 24], but proof of neovasculature formation by sprouting angiogenesis and vascular proliferation was not yet provided. Therefore, the present study was undertaken to investigate in the CAM some of the details of the mechanism of tissue revascularization after PDT. We show that neoangiogenesis occurs by observation of vessel morphology, by immunohistochemical detection of endothelial proliferation markers, and markers of angiogenesis (galectin-1 and vimentin), as well as by molecular profiling using real-time RT-PCR. We also suggest that next to new vessel formation, reperfusion of occluded blood vessels occurs. Understanding of the mechanisms of PDT-induced angiogenesis will help to optimize the improvement of PDT by combination with angiogenesis inhibitors.

\section{Materials and methods}

The in ovo CAM model

Fertilized chicken eggs (Animalco AG, Staufen, Switzerland) were labelled and transferred into a hatching incubator with a relative air humidity of $65 \%$ and a temperature of $37^{\circ} \mathrm{C}$. This incubator was equipped with an automatic rotator (Savimat, Chauffry, France). On EDD 3, a hole of approximately $3 \mathrm{~mm}$ in diameter was opened in the eggshell and covered with a Laboratory Wrapping Film, Parafilm ${ }^{\circledR}$ (Pechiney, Menasha, USA) to prevent dehydratation and possible infections. The eggs were then returned to the incubator in a static position until use. On embryo developmental day (EDD) 11, the hole in the shell above the air pouch of the egg is extended to a diameter of approximately $3 \mathrm{~cm}$ in order to provide better access to the chorioallantoic membrane for the experiments.

For the topical application of compounds, polyethylene rings were deposited on the CAM. These polyethylene rings (diameter $5 \mathrm{~mm}$; wall thickness $0.5 \mathrm{~mm}, 1 \mathrm{~mm}$ height) confine the topical drug to only the small part of the CAM surface inside the ring. Eggs were placed under an epi-fluorescence microscope described below and PDT was performed. After the treatment the eggs were numbered, covered and returned to the incubator.

\section{Microscopy and image acquisition}

Microscopic observation of CAM vasculature and the light irradiation for PDT were performed with an epi-fluorescence Eclipse $600 \mathrm{FN}$ microscope, as described previously $[17,25]$, equipped with a Plan Apo 4/0.2, working distance 20 objective (Nikon, Japan). Illumination was provided by a $100 \mathrm{~W}$ high pressure $\mathrm{Hg}$-arc lamp. Light doses were adjusted with neutral density filters and measured with a calibrated Field-Master GS power meter (Coherent, Santa Clara, USA). For exciting and detecting Visudyne ${ }^{\circledR}$, the microscope was equipped with a BV-2A filter set $\left(\lambda_{\mathrm{ex}}=\right.$ $420 \pm 20 \mathrm{~nm}, \lambda_{\mathrm{em}}>470 \mathrm{~nm}$, Nikon, Japan). For detecting FITC, light was filtered for excitation at $470 \pm 20 \mathrm{~nm}$ and a long-pass emission filter was used for detection of the 
fluorescence $(\lambda>520 \mathrm{~nm}$, Nikon, Japan). Fluorescence images were acquired with an F-view II 12-bit monochrome Peltier-cooled digital CCD camera driven with analySIS DOCU software from Soft Imaging System (Muenster, Germany).

\section{Visudyne ${ }^{\circledR}$-Photodynamic therapy}

This part of the study aimed at performing PDT to observe the evolution of the vascular network, especially in terms of vascular occlusion, during the 2 days following treatment. For this purpose, on EDD 11, the egg opening was extended to $3 \mathrm{~cm}$ in diameter, and a volume of $10 \mu \mathrm{l}$ of Visudyne $^{\circledR}$ (the liposomal formulation of verteporfin [26], Novartis Pharma, Inc., Hettlingen, Switzerland) was intravenously administered through a 33-gauge needle fitted to a $100 \mu$ l syringe (Hamilton, Reno, USA) into the main vessel of the CAM. This corresponds to $0.20 \mathrm{mg}$ verteporfin per $\mathrm{kg}$ embryo weight. One minute after injection, the site with vessels of diameter between 5 and about $70 \mu \mathrm{m}$ was irradiated with a light dose of $20 \mathrm{~J} / \mathrm{cm}^{2}$ $\left(\lambda_{\mathrm{ex}}=420 \mathrm{~nm}, \lambda_{\mathrm{em}}>470 \mathrm{~nm}\right)$ with irradiance of $60 \mathrm{~mW} /$ $\mathrm{cm}^{2}$. The irradiation area was $0.02 \mathrm{~cm}^{2}$ as delimited by an optical diaphragm, within the area inside the polyethylene ring, which defined the area of possible topical drug administration. The site was photographed at the beginning and at the end of irradiation. Subsequently, the egg opening was sealed with parafilm and the embryo was further incubated for $24 \mathrm{~h}$ before assessing the PDT-induced damage. The conditions used here in the CAM model are the same as those that were previously selected in other studies [14]. They lead to similar angio-occlusion efficiency as observed after Visudyne ${ }^{\circledR}$-PDT in the human eye at the most prevalent clinical conditions.

Optimal PDT-induced closure of vasculature in the CAM is defined as closing the same diameter as the choroidal neovessels ( $\mathrm{CNV}$ ) that are targeted in PDT in the case of wet age-related macular degeneration (i.e. $<70 \mu \mathrm{m}$ in diameter), while leaving the larger vessels open. "Standard" clinical PDT of CNV conditions are a verteporfin dose of $6 \mathrm{mg} / \mathrm{m}^{2}$ of body surface $(0.15 \mathrm{mg} / \mathrm{kg})$ and irradiation with $50 \mathrm{~J} / \mathrm{cm}^{2}$ at $689 \mathrm{~nm}$, using an irradiance of $600 \mathrm{~mW} / \mathrm{cm}^{2}, 15 \mathrm{~min}$ after the start of the slow 10-min infusion of the drug [27]. The transparency of the CAM allows using blue light (excitation at $420 \mathrm{~nm}$ ) in order to excite the benzoporphyrin. In order to verify the efficacy of the blood flow stasis and the vascular occlusion induced by PDT under these conditions, observation of the vasculature was undertaken daily for the 2 days following the illumination by means of fluorescence angiographies. These were performed after i.v. injection of $20 \mu \mathrm{l}$ of a solution containing of FITC-dextran $(20 \mathrm{kDa}, 25 \mathrm{mg} / \mathrm{ml})$, followed by fluorescence angiography using light from an $\mathrm{Hg}$-arc lamp filtered for excitation at $470 \pm 20 \mathrm{~nm}$ and with a long-pass emission filter $(\lambda>520 \mathrm{~nm})$ for observing the fluorescence. In order to increase the quality of the recorded angiographs, a light absorber, in the form of India ink, was injected $(30 \mu \mathrm{l})$ into the extra-embryonic cavity just under the deposited polyethylene ring. The purpose of this second injection was to decrease the influence of the CAM autofluorescence background, which changes rapidly with time due to the embryo's movement. The India ink was filtered using a sterile cellulose acetate membrane $(0.2 \mu \mathrm{m}$ pores, Renner GMBH, Darmstadt, Germany) just before injection. Between the treatment and this measurement, the eggs were again re-covered with parafilm, maintained in the dark and returned to the incubator.

In order to perform quantitative real-time RT-PCR experiments on the PDT effect, Visudyne ${ }^{\circledR}$-PDT was performed on a large area of the CAM $\left(0.5 \mathrm{~cm}^{2}\right)$ at EDD 11. To that end, an Oxxius laser (Oxxius S.A., Lannion, France) was used, coupled to the frontal light distributor fiber, SN FD1-1351 (Medlight S.A., Ecublens, Switzerland) with an excitation wavelength of $405 \mathrm{~nm}$ (applied light dose of $20 \mathrm{~J} / \mathrm{cm}^{2}$ and the irradiance of $25 \mathrm{~mW} / \mathrm{cm}^{2}$ ). After PDT, embryos were numbered, covered with parafilm and returned to the incubator. $48 \mathrm{~h}$ after PDT (EDD 13) the treated CAMs were fixed overnight in Zn-fixative solution, dried and frozen until the RNA extraction procedure.

Combining of Visudyne ${ }^{\circledR}$-PDT with Avastin ${ }^{\circledR}$

This part of the study was designed to observe the prolonged vascular occlusion, due to combination therapy consisting of photodynamic therapy followed by antiangiogenesis. Experiments of Visudyne ${ }^{\circledR}$-PDT were conducted as described above. Subsequently, $24 \mathrm{~h}$ post PDT, treated CAMs were i.v. injected with $20 \mu \mathrm{l}$ of a solution containing FITC-dextran $(20 \mathrm{kDa}, 25 \mathrm{mg} / \mathrm{ml})$, and observed by fluorescence angiography using light from an $\mathrm{Hg}$-arc lamp filtered for excitation at $470 \pm 20 \mathrm{~nm}$ and with a long-pass emission filter $(\lambda>520 \mathrm{~nm})$. After that, Avastin $^{\circledR}$ (bevacizumab), a product of Genentech, San Francisco, USA, was administered topically $(20 \mu 1,1.7 \mathrm{mg} /$ $\mathrm{ml} ; 34 \mu \mathrm{g}$ (embryo) in the polyethylene ring onto the CAM surface. In order to observe vascular regrowth after PDT under these conditions, observation of the vasculature was undertaken also $48 \mathrm{~h}$ post PDT by means of FITC-dextran fluorescence angiographies (as described above).

Immunohistochemistry

CAMs were fixed overnight in Zn-fixative [28] and embedded in paraffin. $4 \mu \mathrm{m}$ sections were cut, dewaxed, and dehydrated. Endogenous peroxidase activity was blocked with $0.3 \%$ hydrogen peroxide in methanol for 
30 min. Next, antigen retrieval was performed with a mixture of $2 \mathrm{M} \mathrm{HCl}$ and $0.2 \%$ Triton X-100 in tris buffered saline (TBS) for $30 \mathrm{~min}$ at room temperature, except for detection of smooth muscle actin (SMA). Slides were blocked with $10 \%$ normal goat serum and $1 \%$ BSA in PBS for $15 \mathrm{~min}$, and subsequently incubated overnight with primary antibodies against Ki-67 (clone MIB-1, Dako, Glostrup, Denmark), $\alpha \mathrm{V} \beta 3$-integrin (clone LM609, Chemicon/Millipore, Amsterdam, The Netherlands), galectin-1 (rabbit polyclonal antibody, Peprotech, London, United Kingdom), vimentin (clone V9, Dako, Glostrup, Denmark), smooth muscle actin (SMA, clone 1A4, Dako, Glostrup, Denmark), and ICAM-1 (clone 166623, R\&D Systems Europe Ltd., Abingdon, United Kingdom). Slides were washed three times with TBS between the antibody incubations. Visualisation was performed with either Power Vision poly-HRP kit (Immunologic, Duiven, The Netherlands) or EnVision + System-HRP kit (Dako, Glostrup, Denmark, only for smooth muscle actin and vimentin). This was followed by the development of the staining with 3,3'-Diaminobenzidine (DAB, Sigma Chemicals, The Netherlands) chromogenic substrate. Subsequently the slides were counterstained with haematoxylin, dehydrated and mounted in DePex mounting medium.

\section{RNA isolation and cDNA synthesis}

Total RNA was isolated from CAM sections using the RNeasy RNA isolation kit (Qiagen, Venlo, The Netherlands) according to the supplier's protocol. Prior to column loading, samples were carefully homogenized in RLT buffer (Qiagen, Venlo, The Netherlands). Possible genomic DNA contaminations were removed by on column DNAse treatment with the RNase-free DNAse set (Qiagen, Venlo, The Netherlands). RNA quality and quantity were checked by spectrophotometry (NanoDrop, Thermo Scientific), and $1,000 \mathrm{ng}$ RNA was used as input for first-strand cDNA synthesis using an iScript cDNA synthesis kit (Bio-Rad Laboratories, The Netherlands) according to the manufacturers' instructions. Reactions were diluted to $50 \mu \mathrm{l}$ and stored at $-20^{\circ} \mathrm{C}$ until use.

\section{Primer design}

Primers (Fig. 7) were targeted against beta-actin (Actin- $\beta$ ), cyclophilin-A (Cyclo-A), vascular endothelial growth factor A (VEGF-A), vascular endothelial growth factor receptors 1 and 2, (VEGFR-1, -R-2), neuropilin-2 (NRP-2), basic fibroblast growth factor (bFGF), integrin $\beta 3$ (ITGB3), galectin 1 (GAL-1) and vimentin (VIM). The primers were specific for chicken (Gallus gallus) sequences and selected based on the following requirements: (1) primer melting temperature of approximately $60^{\circ} \mathrm{C}$, (2) GC content of approximately $55 \%$, (3) preferably no $\mathrm{G}$ at the $5^{\prime}$ end, (4) avoid runs of more than three identical nucleotides, and (5) amplicon length of approximately 100 nucleotides. Specificity and cross-reactivity were checked with the Basic Local Alignment Search Tool (BLAST; http:// www.ncbi.nlm.nih.gov/BLAST). All primers were synthesized by Sigma-Genosys, The Netherlands.

\section{Quantitative real-time RT-PCR}

Quantitative real-time RT-PCR (qRT-PCR) was performed in $25 \mu \mathrm{l}$ reactions, containing $1 \times$ iQ SYBR Green supermix (Bio-Rad Laboratories, The Netherlands), 200 $\mathrm{nM}$ forward and reverse primer (Fig. 7c) and $1.5 \mu \mathrm{l}$ cDNA. Reactions were run on a CFX96 thermal cycler (Bio-Rad Laboratories, The Netherlands), and consisted of an initial denaturation for $10 \mathrm{~min}$ at $95^{\circ} \mathrm{C}$ followed by 50 cycles of $15 \mathrm{~s}$ at $95^{\circ} \mathrm{C}$ and $1 \mathrm{~min}$ at $60^{\circ} \mathrm{C}$. Following each run, melting curves were generated to verify specific product formation. Data were analysed using CFX Manager software (Bio-Rad Laboratories, The Netherlands) and the expression of each target gene was quantified relative to the expression of the reference genes (Actin- $\beta$ and Cyclo-A) [29].

\section{Results}

Morphological characterization

The aim of this study was to investigate in detail some of the vascular events after Visudyne ${ }^{\circledR}$-PDT. To that end, we performed PDT at the stage in which the CAM is already fully developed-EDD 11-and contains a vessel network with a regular capillary plexus (see Figs. 1a and 2a) [30]. We used previously optimized PDT protocols, which caused an almost total occlusion of the treated vessels [14]. Visudyne ${ }^{\circledR}$-PDT caused thromboembolic events, and vascular constriction leading to obstruction of both large vessels and the capillary bed, which resulted in a complete perfusion arrest (see Fig. $1 \mathrm{~b}$ and e). To evaluate the induction, and maintenance, of vascular occlusion after PDT, as well as to study the neovascularization and reperfusion processes, the treated area of the CAM was observed for 2 days post PDT. $48 \mathrm{~h}$ after Visudyne ${ }^{\circledR}$-PDT a full revascularization had occurred (see Fig. 1c and f).

As has been previously described [14, 23], PDT causes the induction of inflammation and angiogenesis processes leading to development of a new functional vascular bed. After $24 \mathrm{~h}$ we observed that revascularization of the treated area starts by sprouting angiogenesis from existing vessel arches outside the treatment zone (see Fig. 2c and d, zone 1), into the angiogenic area. Cellular protrusions of 

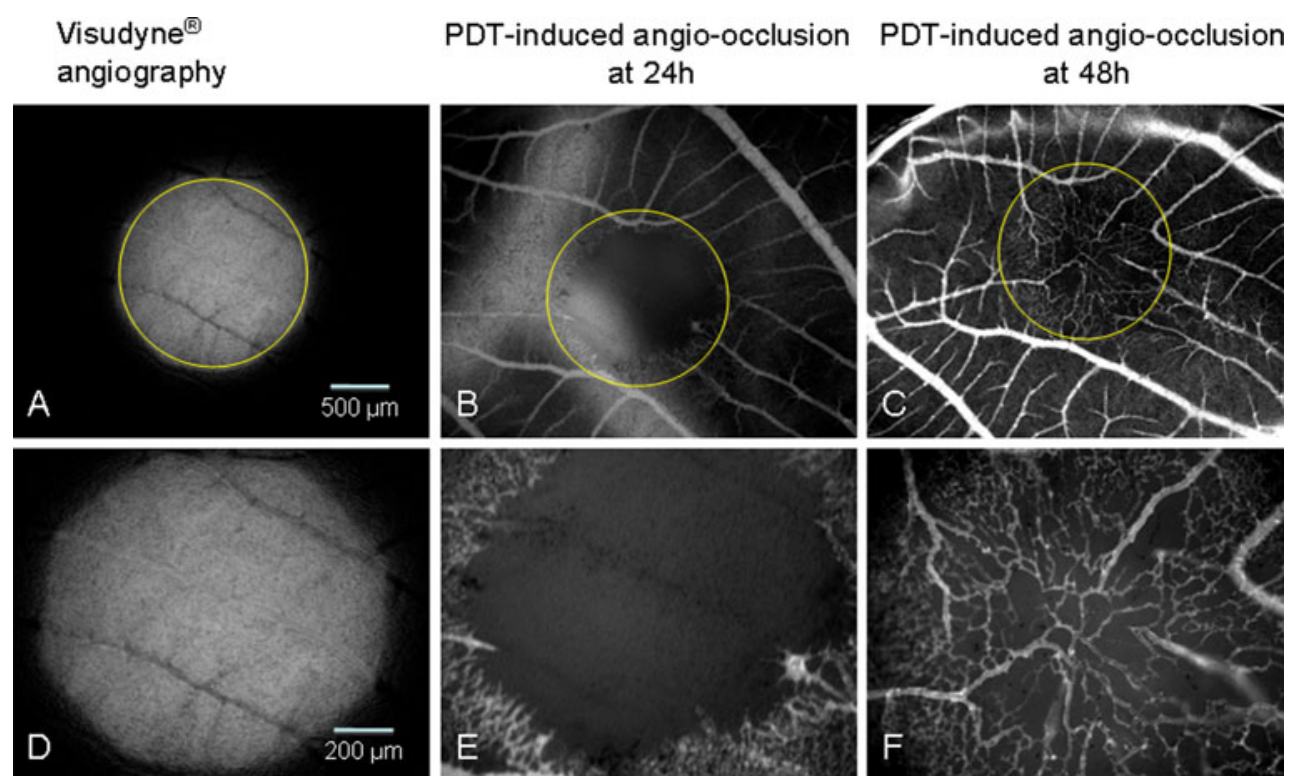

Fig. 1 Angiography images of the chorioallantoic membrane (CAM) vasculature before and after PDT. Images of the CAM before PDT (a and d) are visualized by Visudyne ${ }^{\circledR}$ fluorescence angiography $\left(0.20 \mathrm{mg} / \mathrm{kg}\right.$ embryo weight, $\left.\lambda_{\mathrm{ex}}=420 \mathrm{~nm}, \lambda_{\mathrm{em}}>470 \mathrm{~nm}\right)$. PDT was performed at a light dose of $20 \mathrm{~J} / \mathrm{cm}^{2}$ and an irradiance of 60 $\mathrm{mW} / \mathrm{cm}^{2}$; drug-light interval: $1 \mathrm{~min}$ ). Pictures $\mathbf{b}$ and $\mathbf{c}$ (objective $4 \times$ ), and $\mathbf{e}$ and $\mathbf{f}$ (the same treated area, objective $10 \times$ ) are visualized by FITC-dextran fluorescence angiography $(25 \mathrm{mg} / \mathrm{kg}, 20 \mathrm{kDa}$,

the leading edge tip cells can be seen (see Fig. $2 b$ arrow I-III, and c arrow I). It is also observed that larger vessels (diameter $30-100 \mu \mathrm{m}$ ) that have been occluded by the PDT-induced thrombotic events get reperfused (see Fig. 2b and c, arrow IV), while newly developing small vessels (Fig. 2d, zone 2, arrow V) replace the original capillary plexus (like in zone 3 ).

After $48 \mathrm{~h}$ the area is repopulated with functional newly grown and reperfused vessels. This new vascular bed does not resemble the morphology of the original capillary plexus (see Fig. 2c and d, zone 3, in particular for vessels with diameter 3-5 $\mu \mathrm{m}$ ), but instead, consists of larger vessels (see Figs. 2d, zone 2, and 1f, typically vessel diameter 5-30 $\mu \mathrm{m}$ ) with a more tortuous morphology. Besides a different morphology, blood flow in these newly formed vessels is slow and inefficient, sometimes leading to halted or even reversed flow.

\section{Histological characterization}

In order to further investigate the fate and features of the vasculature after Visudyne ${ }^{\circledR}$-PDT, histology was performed on Zn-fixed and paraffin embedded CAMs. Fig. 3a shows the gross histological appearance of the CAM $48 \mathrm{~h}$ after PDT over an area of $6.2 \mathrm{~mm}^{2}$. This section is stained for smooth muscle actin to show the mature vasculature. As can be seen, the treatment induces wounding of the CAM $\left.\lambda_{\mathrm{ex}}=470 \mathrm{~nm}, \lambda_{\mathrm{em}}=520 \mathrm{~nm}\right)$. Images $\mathbf{b}$ and e were taken $24 \mathrm{~h}$ after PDT and show full angio-occlusion in the PDT area. Images c and f were taken $48 \mathrm{~h}$ after PDT, showing the vascular regrowth. CAM area in pictures $\mathbf{a}-\mathbf{c}$ is $3.5 \times 2.8 \mathrm{~mm}$ (objective $4 \times$ ), in $\mathbf{d}-\mathbf{f}$ is $1.4 \times 1.12 \mathrm{~mm}(1,280 \times 1,024$ pixels with 4,095 grey levels, objective $10 \times$ ). In order to increase the contrast India ink was injected $(30 \mu \mathrm{l})$ into the extra-embryonic cavity right under the treated area

tissue (the area between the indicated arrows, Fig. 3a) leading to a thinner membrane as compared to the untreated area. In panel B an equivalent part of the CAM is shown as an angiography, showing the differences in the vasculature between normal and PDT treated areas (Fig. 3b).

Immunohistochemical staining of the Ki-67 proliferation marker was performed, as well as detection of $\alpha \mathrm{V} \beta 3$ integrin as a marker of immature and angiogenic blood vessels. Ki-67 was found to be expressed in the vasculature, $48 \mathrm{~h}$ after PDT in the exposed area of the CAM (Fig. 4a). This result implies that new vasculature is formed by sprouting angiogenesis, requiring proliferation of endothelial cells. Moreover, we found expression of $\alpha \mathrm{V} \beta 3$-integrin in the vessels of the PDT treated CAM after $48 \mathrm{~h}$, but not in the non-treated control areas (see Fig. $4 \mathrm{~b}$ and c).

The previously identified markers of angiogenic blood vessels, vimentin [31] and galectin-1 [32], were detected in the CAM. Our data suggest that these markers are overexpressed in the newly formed vasculature in the PDT area as compared to the untreated area (Fig. 5). In addition, a molecule that is described as being suppressed in angiogenic endothelium [33] and serves more as a differentiation marker, i.e. ICAM-1, was found at lower levels of expression in the PDT area, as compared to the untreated CAM (Fig. 5). These data together demonstrate that the 

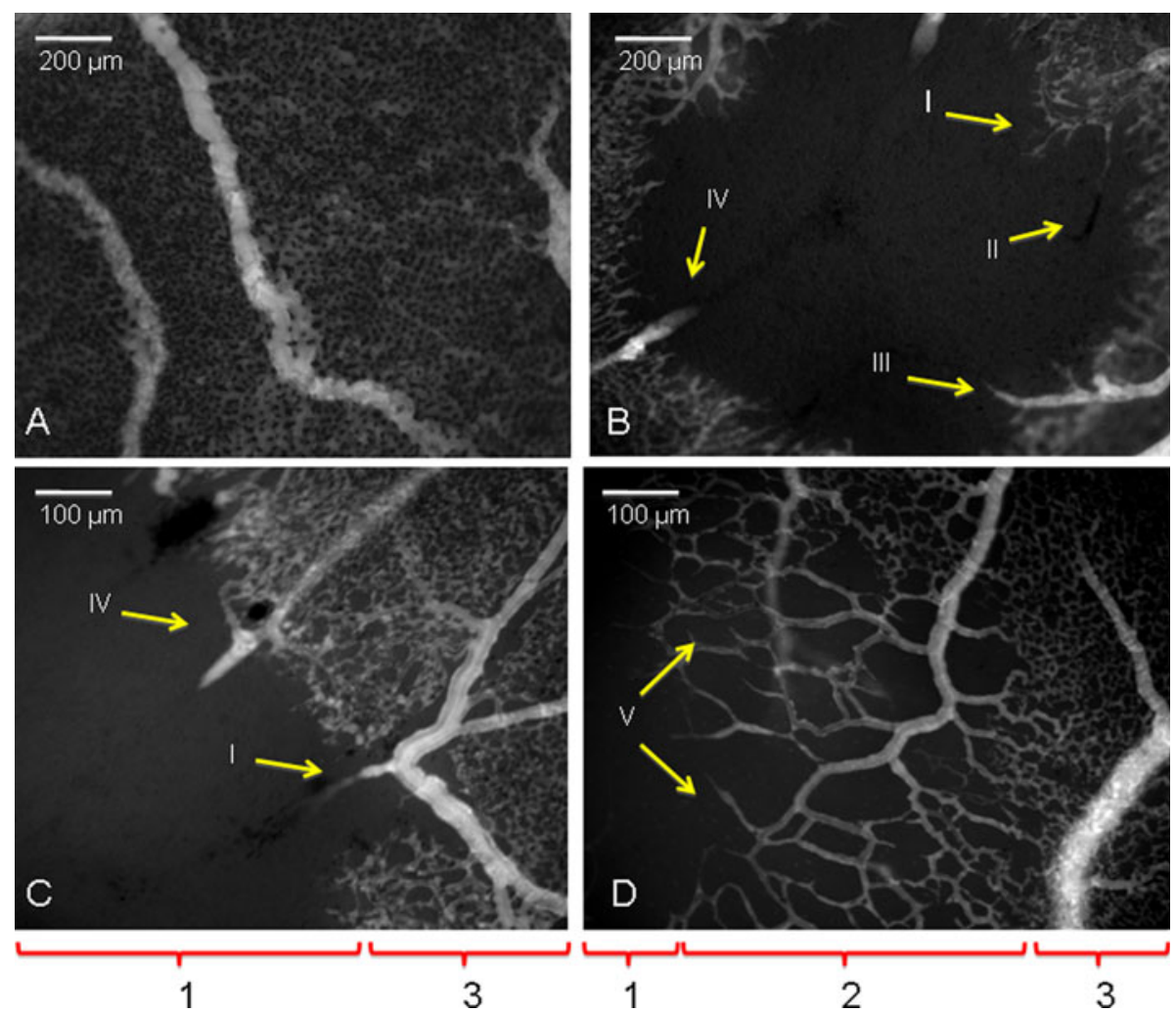

Fig. 2 Angiography images of the CAM after PDT visualized by FITC-dextran fluorescence angiography. a Normal (untreated) small vessels and capillary network, taken at EDD 13 . b and c $24 \mathrm{~h}$ post PDT (EDD 12), whereas d was taken $40 \mathrm{~h}$ post PDT (EDD 12/13). Zones marked below pictures $\mathbf{c}$ and $\mathbf{d}$ represent: (1) non-regrown zone, (2) post PDT-regrown zone and (3) non-treated zone on the CAM. Phenomena of the regrowth process: (I) sprouting originating

vasculature contains angiogenically-activated blood vessels, and suggests that the formation of neovasculature occurs after application of PDT.

Evidence for a prominent role of the formation of new blood vessels in the CAM after PDT was further obtained by use of the well-known and clinically used angiogenesis inhibitor Avastin ${ }^{\circledR}$. Although this anti-VEGF antibody was designed to bind human VEGF, a significant activity against chicken VEGF has also been reported [14]. Combination treatment of the CAM starting with Avastin ${ }^{\circledR} 24 \mathrm{~h}$ after PDT hours results in a considerable inhibition of the regrowth of the vasculature $48 \mathrm{~h}$ post PDT (Fig. 6d), as compared to the observations without Avastin ${ }^{\circledR}$ (Fig. 6b). This is in agreement with our previous findings [14].

Transcriptional expression of angiogenesis genes

To investigate and prove the induction and regulation of angiogenesis genes after PDT, we determined mRNA expression of a set of angiogenesis related genes, such as for VEGF-A, bFGF, VEGF receptors VEGFR-1 and -2, neuropillin-2, and endothelial angiogenesis markers, such

from the loop of pre-existing vessels, (II) dead-ended sprout, (III) filopodia with tip cell, (IV) recanalization of pre-existing, lumenreduced vessels within PDT-treated area, $(V)$ ongoing pillar building in neovascular meshes. In order to increase the contrast India ink was injected $(30 \mu \mathrm{l})$ into the extra-embryonic cavity right under the treated area. Image size: $1.4 \times 1.12 \mathrm{~mm}(1,280 \times 1,024$ pixels with 4,095 grey levels)

as integrin $\beta 3$, vimentin and galectin-1. RNA was isolated from control CAMs (EDD 11 and EDD 12), as well as from CAMs extracted $6 \mathrm{~h}$ (EDD 11), $24 \mathrm{~h}$ (EDD 12), or $48 \mathrm{~h}$ (EDD 13) after application of PDT. Expression of the tested genes did not differ significantly in the control groups (EDD 11 and EDD 12). These results were therefore all incorporated into a single control group. Fig. $7 \mathrm{a}-\mathrm{h}$ show the relative transcriptional expression of the angiogenesis genes versus the reference genes beta-actin (ActinB) and Cyclophilin-A (Cyclo-A).

VEGF-A was observed to be significantly upregulated by approximately 2 -fold immediately after PDT (6 h, Fig. 7a). Interestingly, this expression was normalized to control levels after 24 and stayed unchanged at 48 h. For bFGF a similar expression profile was found (Fig. 7b), indicating that angiogenesis is induced by a rapid spiking of activators, but that this signal is transient. A slower regulation is found for the VEGF receptors. VEGFR-1 and VEGFR-2 are both significantly induced by PDT as well. While their expression was found to be increased by factor of 13.5 (VEGFR-1) respectively a factor of 3 (VEGFR-2) at $24 \mathrm{~h}$ after PDT, the increase of this angiogenic environment remained at least 


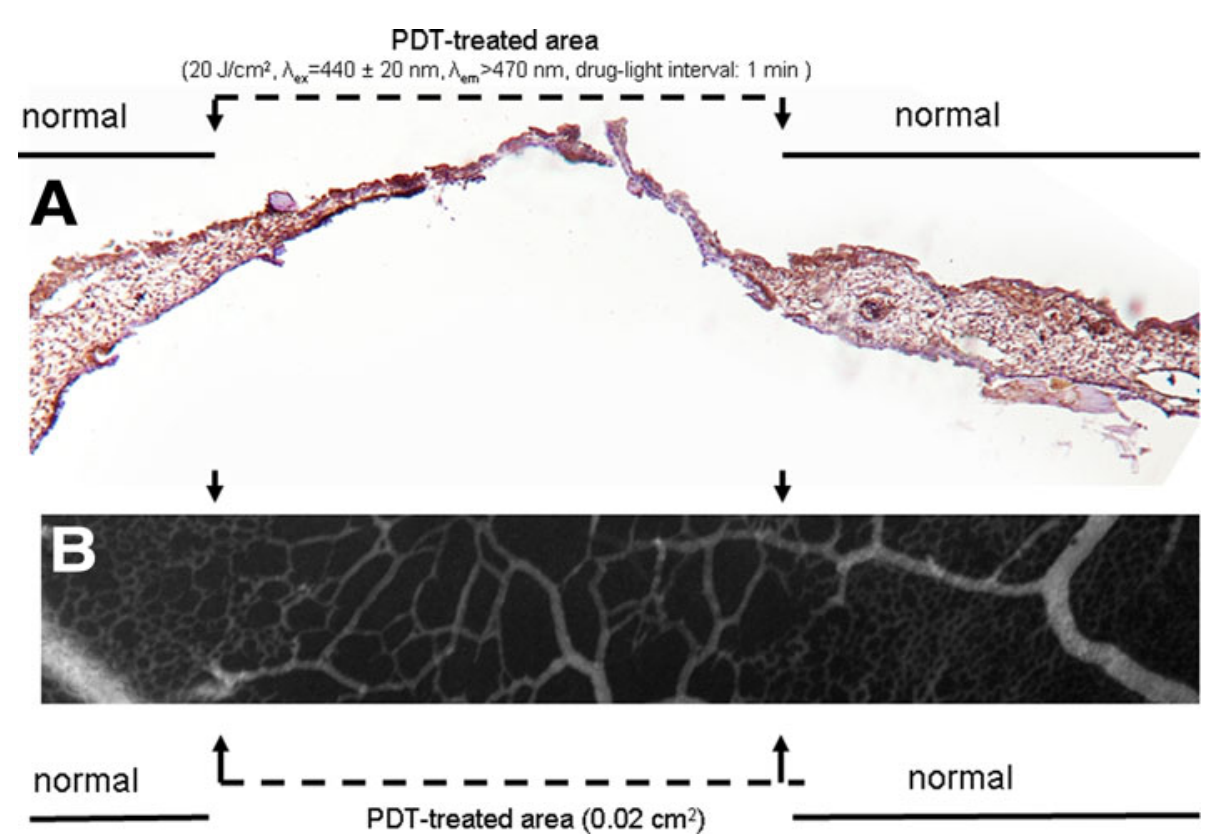

Fig. 3 Representation of a PDT-treated area and a non-treated CAM are shown in an immunohistochemical section and a fluorescence angiography $48 \mathrm{~h}$ after PDT. a Histological image of the $\mathrm{Zn}$-fixed CAM, after smooth muscle actin (SMA) staining with DAB (brown) and counterstaining with hematoxylin (purple) to visualize the nuclei. It is indicated where PDT is applied and how the tissue morphology

until $48 \mathrm{~h}$ (Fig. 7c and d, respectively). Interestingly, the expression of another VEGF receptor, neuropillin-2 was already significantly upregulated $6 \mathrm{~h}$ after PDT, and peaked after $24 \mathrm{~h}$. This receptor upregulation appears to be transient as well (Fig. 7e). We also tried to measure neuropillin1 , however this receptor was found not to be expressed at detectable levels.

The overexpression of integrin- $\beta 3$ as well as of galectin1 and vimentin as found by immunohistochemistry was confirmed by PCR analysis (Fig. 7f-h).

\section{Discussion}

The current work aimed at studying angiogenesis and neovasculature formation taking place after PDT, as well as the reperfulsion of vessels occluded by PDT. Up to now, there was no consistent and firm proof in the literature that revascularization in the CAM after PDT involves neoformation of vasculature. Several studies reported the observed altered vascular morphology, which is compatible with neo-angiogenesis, but proof of sprouting or vascular proliferation was not shown [14, 23, 24]. Here we present several lines of support for the contribution of sprouting angiogenesis after PDT in the chorioallantoic membrane (CAM) of the chicken embryo. We first showed that the process of sprouting angiogenesis and the presence of changes after PDT (the PDT area is $0.02 \mathrm{~cm}^{2}$ ). b Part of the PDTtreated area visualized by FITC-dextran fluorescence angiography $\left(25 \mathrm{mg} / \mathrm{kg}, 20 \mathrm{kDa}, \lambda_{\mathrm{ex}}=470 \mathrm{~nm}, \lambda_{\mathrm{em}}=520 \mathrm{~nm}\right)$ showing morphologically-modified regrown vasculature in PDT-treated area as compared to the normal non-treated vasculature

guiding tip-cells was readily observable by regular microscopy. Secondly, we found expression of Ki-67 in the vasculature of the PDT treated area by immunohistochemistry. Thirdly, we suggest overexpression of the endothelial angiogenesis markers $\alpha \mathrm{V} \beta 3$-integrin, vimentin and galectin-1, as well as suppression of the endothelial differentiation marker ICAM-1 within the PDT treated area at the protein level, $48 \mathrm{~h}$ post treatment. Fourthly, we demonstrated pharmacological suppression of revascularization by treatment with the anti-VEGF compound Ava$\operatorname{stin}^{\circledR}$. Lastly, molecular profiling by quantitative real-time RT-PCR demonstrated the spiking of the angiogenic growth factors VEGF and bFGF as well as the upregulation of VEGF receptors. In addition, the upregulation of the endothelial angiogenesis markers was confirmed at the transcriptional level.

We performed these studies in the CAM since this model has been used for studying and optimizing the effect of PDT on human choroidal (neo)vessels [16, 34-36]. The CAM has been used for studying the application of PDT for eye diseases, including exudative age-related macular degeneration. Although the application of PDT in some early stage cancers of the upper digestive tract, has been very successful [37, 38], in general applications for oncological diseases have been rather disappointing. Some of these applications can be simulated in the CAM after transplantation of tumor spheroids onto the membrane. The 

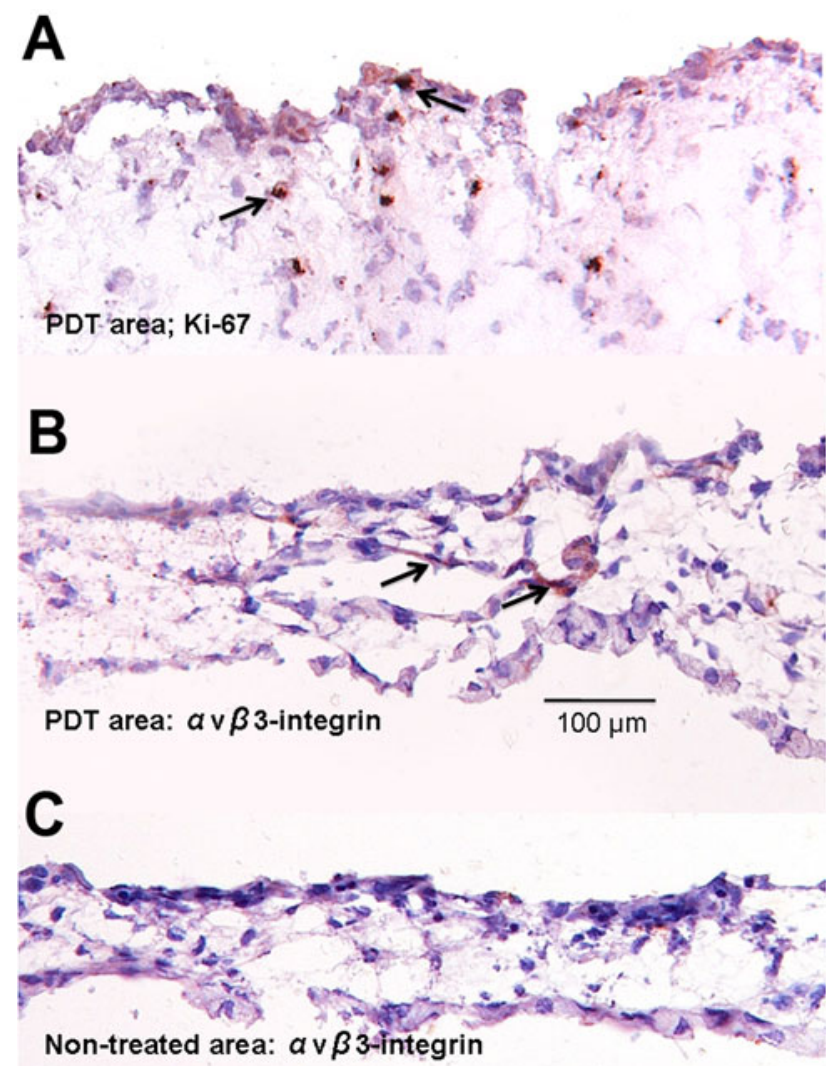

Fig. 4 Immunohistochemical detection of proliferating vasculature and expression of the angiogenesis marker $\alpha \mathrm{V} \beta 3$-integrin in the CAM $48 \mathrm{~h}$ after PDT. a PDT treated CAM stained for the nuclear proliferation marker Ki-67 (DAB, brown, arrows point to the nuclei of proliferating cells). Arrows indicate the positive staining of nuclei of proliferating endothelial cells. b Expression of $\alpha \mathrm{V} \beta 3$-integrin (brown) in a blood vessel after PDT treatment. $\mathbf{c}$ Negative staining for both $\alpha \mathrm{V} \beta 3$-integrin and $\mathrm{Ki}-67$ in the normal non-treated area of the CAM. Counterstaining with hematoxylin (purple) was performed to visualize the nuclei. Scale bar in $\mathbf{b}$ applies for all panels

current study provides therefore also insights and tools for development of PDT for a number of diseases.

Our study, as well as earlier reports, supports the hypothesis that the CAM harbors an efficient vascular regeneration capacity similar to the human eye. After application of PDT, new vessels are formed to replace the original capillary plexus, a process, which is completed within $48 \mathrm{~h}$ (Fig. $2 \mathrm{~b}$ and c). Larger blood vessels were also found to be occluded, but could be recanalized and/or reperfused. This is presumably possible because of the fact that larger vessels are more resistant to PDTinduced occlusion at the applied conditions. The latter observation is consistent with results published by Arroyo et al. [39]. However, it should be noted that we did not quantify the number or percentage of reperfused vessels versus newly formed vasculature in the PDTtreated area.
The architecture of the newly formed vessels is more tortuous and seems to be less organized when compared to the original capillary plexus. This observation is comparable to the tortuous morphology of vessels found in angiogenic tumors, a feature that can be partially changed by neutralization of VEGF [40], with antibody or antibody fragment against this protein. The architecture of tubular structures is determined by the sprouting of new tubes from preexisting ones. The tip cells respond to a gradient of VEGF-A by guided migration, while the proliferative response occurs in the sprout stalk [41]. We showed by PCR profiling that VEGF and VEGF receptors play a role in the PDT induced angiogenesis response. Interestingly, gene expression of both VEGF and bFGF is rapidly induced and already measurable after $6 \mathrm{~h}$, indicative of the "explosive" angiogenic response to the PDT induced stress. After 24 and $48 \mathrm{~h}$, the level of the angiogenic growth factors returns to control levels, but the proangiogenic condition is than maintained by enhanced expression of the growth factor receptors.

Previous studies in the CAM model have shown that exposure to different angiogenic stimuli, including VEGF and bFGF, resulted in increased angiogenic activity [42, 43], and that VEGF and bFGF exibit a strong synergistic activity [44]. Induction of VEGF expression after PDT was also shown in several previous studies in the retinochoroidal area of the human eye $[45,46]$. The induction of both bFGF and VEGF after PDT ( $6 \mathrm{~h}$ post PDT) was found by Schmidt-Erfurth et al. [27]. In this study immunohistopathologic examinations were performed on the eyes of patients who underwent enucleation after PDT. Also in oncological conditions PDT-induction of VEGF was shown. Uehara et al. showed that tumor cells exhibit a significantly higher VEGF expression $6 \mathrm{~h}$ after PDT than those of the untreated control groups [47, 48]. It is interesting to note that the kinetics and amplitude of the growth factor responses, that we found to be both rapid and transient in origin, seem to be identical in other systems. In the Uehara study, VEGF levels subsequently returned to control levels by $24 \mathrm{~h}$ after PDT. In another study by Chang et al. [49] VEGF up-regulation following PDT was monitored in the PC-3 prostate cancer model in immunodeficient mice. A statistically significant increase in VEGF was observed in PDT-treated tumors as early as $1 \mathrm{~h}$ post- PDT, reaching the highest value of 2.5 -fold induction as compared to the control by $6 \mathrm{~h}$ post PDT.

Interestingly, also NRP-2, a transmembrane VEGF coreceptor, which is predominantly expressed in vein endothelial cells, in our studies also showed a rapid significant but rather transient upregulation 6-24 h after PDT. The other tested VEGF receptors, VEGFR-1 and VEGFR-2, were upregulated later ( $24 \mathrm{~h}$ after PDT), and stayed high at least up to $48 \mathrm{~h}$. 
Fig. 5 Immunohistochemical visualization of angiogenesis regulated molecules $48 \mathrm{~h}$ after PDT of the CAM. Zn-fixed and paraffin embedded tissues were stained with antibodies against galectin-1 and vimentin, markers of angiogenesis (DAB, brown). PDT treated tissue is more heavily stained as compared to the normal tissue. Tissues were also stained for intercellular adhesion molecule (ICAM)-1, a marker of endothelial differentiation. For ICAM-1, the PDT treated area is less stained than the normal tissue. Scale bar in lower left panel applies for all panels
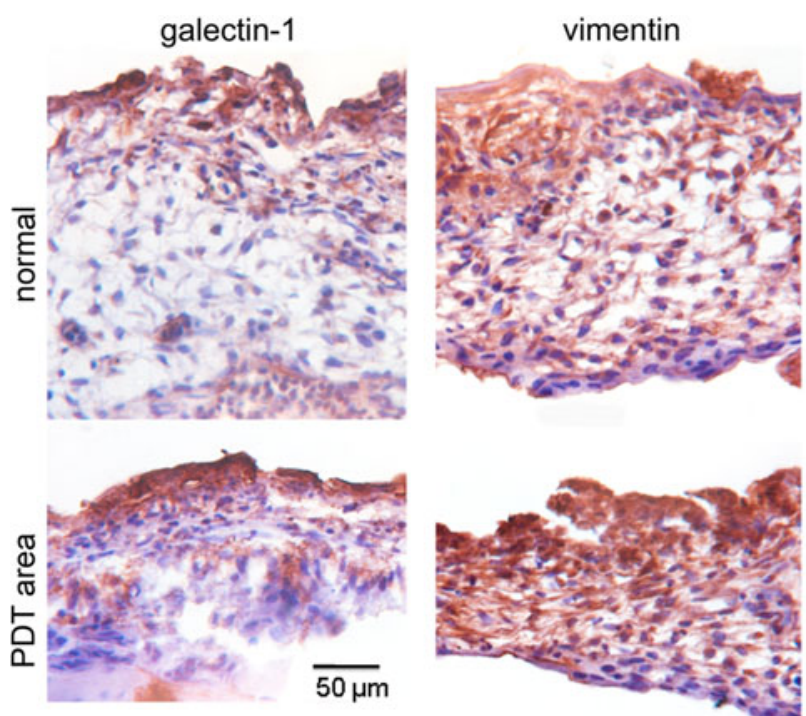

ICAM-1
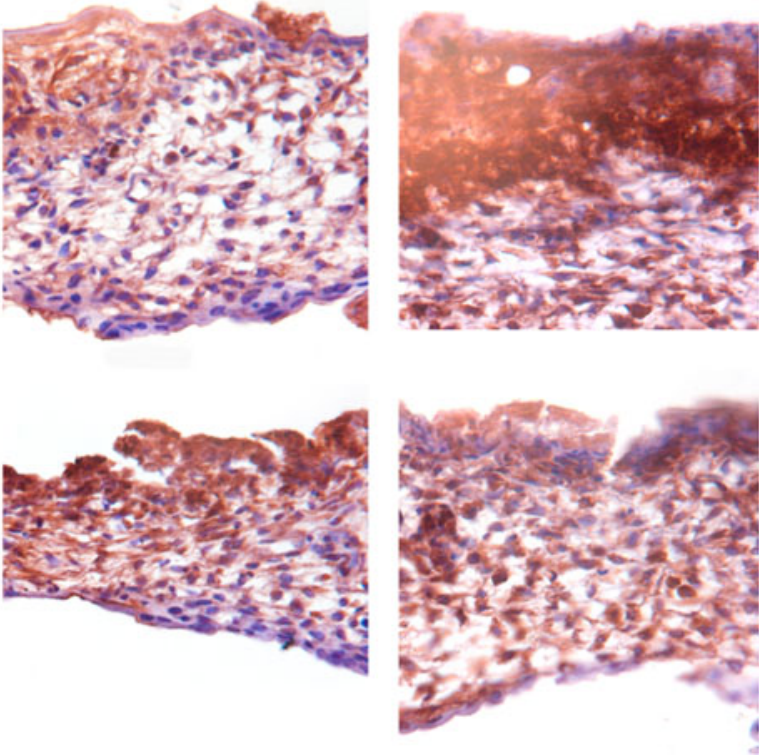

Fig. 6 Images of the CAM vasculature before and $48 \mathrm{~h}$ after PDT. Angiography images of the CAM before (a and $\mathbf{c}$ ) and $48 \mathrm{~h}$ after PDT (b and d). The efficacy of the combination of PDT with treatment with Avastin $^{\circledR}$, administered topically $24 \mathrm{~h}$ after PDT (20 $\mu \mathrm{l}$, $1.7 \mathrm{mg} / \mathrm{ml}$ ) on the PDT-treated area, is shown in $\mathbf{d}$. Vasculature in picture $\mathbf{a}$ and $\mathbf{c}$ is visualized by Visudyne ${ }^{\circledR}$ fluorescence angiography $(0.20 \mathrm{mg} / \mathrm{kg}$ embryo weight, $\lambda_{\mathrm{ex}}=420 \mathrm{~nm}$, $\lambda_{\mathrm{em}}>470 \mathrm{~nm}$ ). Pictures $\mathbf{c}$ and d are visualized by FITCdextran fluorescence angiography $(25 \mathrm{mg} / \mathrm{kg}$, $20 \mathrm{kDa}, \lambda_{\mathrm{ex}}=470 \mathrm{~nm}$, $\lambda_{\mathrm{em}}=520 \mathrm{~nm}$ ). PDT was performed at a light dose of $20 \mathrm{~J} / \mathrm{cm}^{2}$ and an irradiance of 60 $\mathrm{mW} / \mathrm{cm}^{2}$. Black background color is obtained by India ink injection $(30 \mu \mathrm{l})$ into the extraembryonic cavity right under the treated area. Circles indicate the PDT-treated area. Scale bar in A applies for all panels
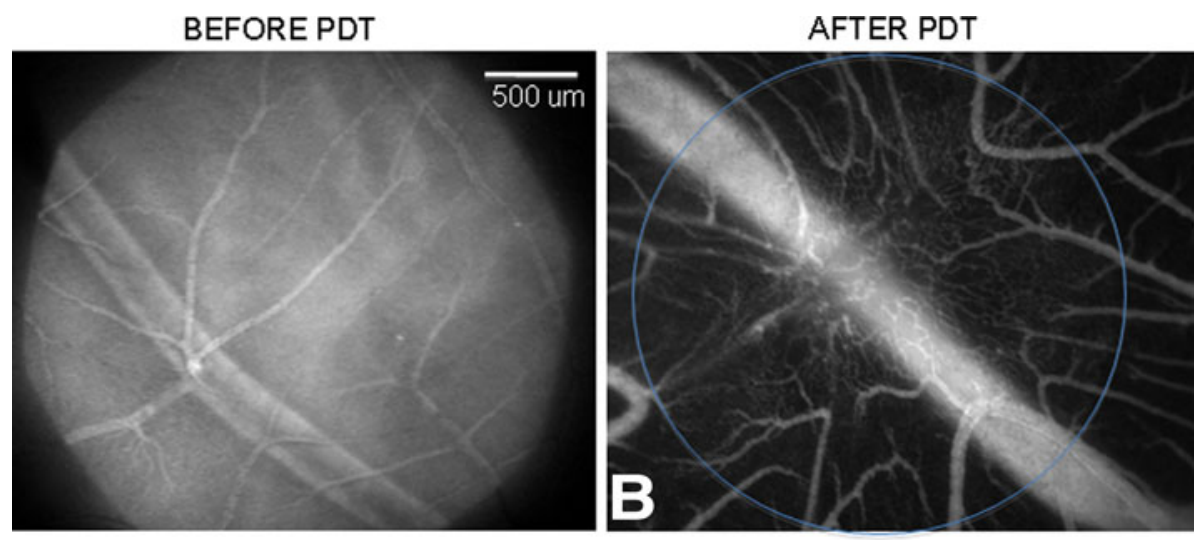

PDT without Avastin ${ }^{\circledR}$
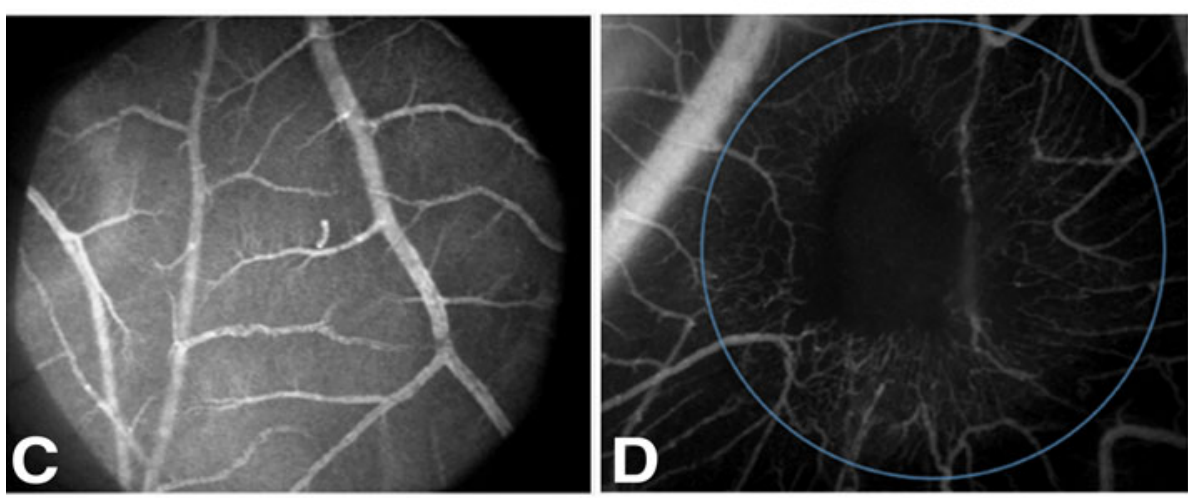

PDT with Avastin ${ }^{\circledR}$
The kinetics and levels of upregulation of these angiogenic stimuli post PDT will help to provide useful information on the optimalization of the order and timing of antiangiogenesis treatment when combined with PDT in order to enhance the therapeutic effects [50]. We have recently demonstrated improvement of PDT with ranibizumab, when applied $24 \mathrm{~h}$ after PDT [14]. Based on the PCR results obtained in the present study we expect an earlier VEGF response, suggesting that an earlier addition may be beneficial in the improvement of this combination therapy.

In order to find proof for neo-angiogenesis we also studied the expression of markers of angiogenic 
Fig. 7 Real-time RT-PCR molecular profiling of the CAM after PDT. Relative transcript expression in the CAM versus reference genes: Actin- $\beta$ and Cyclo-A for the following treatment groups: control (untreated), $6 \mathrm{~h}$ post PDT, $24 \mathrm{~h}$ post PDT, and $48 \mathrm{~h}$ post PDT. a VEGF-A, b bFGF, $\mathbf{c}$ VEGF receptor 1 , d VEGF receptor 2 , e neuropillin-2, $\mathbf{f}$ integrin $\beta 3$-subunit, g galectin-1, $\mathbf{h}$ vimentin. The table shows the primer sequences used for the molecular profiling of the CAM
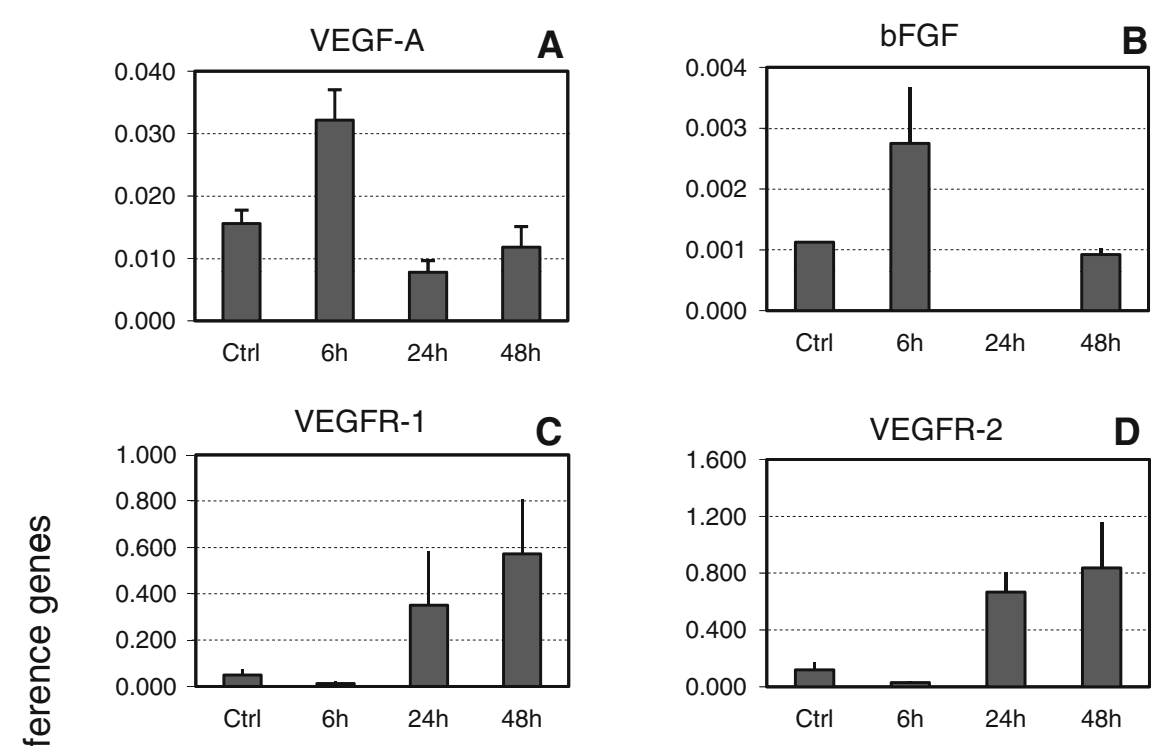

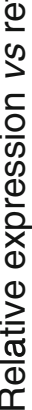
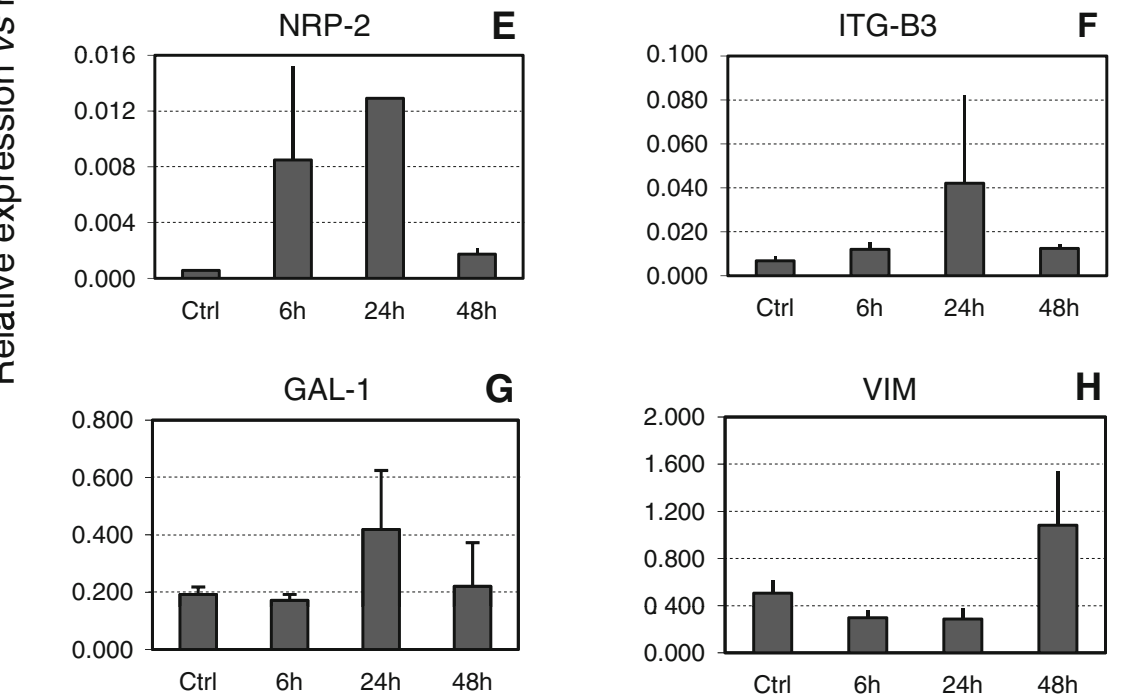

\begin{tabular}{|l|c|c|c|c|}
\hline \multicolumn{1}{|c|}{ Target } & Bases & Forward primer 5'-3' & Bases & Reverse primer 5'-3' \\
\hline Actin-3 & $218-239$ & AGACAGCTACGTTGGTGATGAA & $351-370$ & 'GCTCCTCAGGGGCTACTCT \\
\hline Cyclo-A & $397-414$ & AAGGAGGGGATGAACGTG & $457-491$ & AGCTGCCCGCAGTTGGA \\
\hline VEGF-A & $557-577$ & GACCTGTAAATGTTCCTGCAA & $684-704$ & AGAAATCAGGCTCCAGAAACA \\
\hline bFGF & $1736-1755$ & TCACGCCTTACAGACACCCT & $1856-1876$ & AGGGAGATGTTACGGAGAATG \\
\hline VEGFR-1 & $3760-3780$ & TCGACACTATCTTCACAGCGG & $3837-3854$ & GCTTCTGCAGTTTGGGCT \\
\hline VEGFR-2 & $1736-1755$ & TCACGCCTTACAGACACCCT & $1856-1876$ & AGGGAGATGTTACGGAGAATG \\
\hline NRP-2 & $693-712$ & CACTAAGATGCCATCGGACA & $864-883$ & CACTGATCTGCATGTTGGAG \\
\hline ITG-B3 & $2281-2298$ & CCGCTTCGAGGAGGAGAA & $2377-2396$ & CAGCATCCTACATGTTCCCA \\
\hline GAL-1 & $210-231$ & CAACTCAAAGAAAATGGAAGAG & $277-296$ & AAAGTGATCTCTATTGGGGC \\
\hline VIM & $1198-1219$ & GGAGAAGAGAGCAGGATTAACA & $1266-1286$ & TCAACAATTGGCTGAGACTCA \\
\hline
\end{tabular}

endothelium. First of all, we found overexpression of $\alpha \mathrm{V} \beta 3$-integrin, an activation marker on endothelium [51], in the PDT area of the CAM after $48 \mathrm{~h}$. PCR analysis of the $\beta 3$ subunit of this integrin suggested confirmation of this response. Galectin-1 and vimentin were used as other activation markers. Galectins are a group of mammalian 
beta-galactoside binding proteins with diverse functions that are not yet fully defined. It has been shown that galectins have intracellular regulatory roles in RNA splicing, act to inhibit or induce apoptosis, stimulate cell proliferation and differentiation, and regulate the cell cycle. Galectin-1 was previously found to function as the endothelial receptor for anginex, a novel peptide angiogenesis inhibitor [32]. In our study, galectin-1 expression was studied. Although not exclusively expressed in the vasculature, as is also the case in human and mouse tissues, we found galectin-1 to be slightly overexpressed in the newly formed vasculature in the PDT area as compared to the untreated area $24 \mathrm{~h}$ post treatment (Fig. 5). This finding was confirmed by PCR analysis.

Also vimentin was studied since it was reported to be overexpressed in angiogenic endothelium [31]. We found both at the protein and mRNA levels overexpression in the PDT area. Interestingly, vimentin cleavage has been reported in response to various inducers of apoptosis, such as ionizing radiation [52] and PDT [53]. Since vimentin is overexpressed in tumor endothelial cells [31], vimentin cleavage may be used as a diagnostic tool to assess therapeutic efficacy of PDT as well as apoptotic changes in certain tumors treated with PDT.

Collectively, our results demonstrate that PDT induces angiogenesis, involving among other growth factors, VEGF and VEGF signaling. It is also shown that the angiogenesis process resulting from Visudyne ${ }^{\circledR}$-PDT involves both vascular neoformation, as well as reperfusion of vessels, the former resulting in replacement of the capillary plexus, while the latter occurs in the larger blood vessels. The current results contribute to the possible further improvement of PDT results by optimizing the combination with angiogenesis inhibition. In particular the possibility of further optimization of the timing of the two therapeutic modes is indicated by the present results [54].

Acknowledgments The authors are grateful for financial support from Dr. Julia Jacobi. The authors want to thank Dr. Jean-Pierre Ballini, Dr. Georges Wagnières and Dr. Witold W. Kilarski for expert technical advice.

Open Access This article is distributed under the terms of the Creative Commons Attribution Noncommercial License which permits any noncommercial use, distribution, and reproduction in any medium, provided the original author(s) and source are credited.

\section{References}

1. Radu A, Wagnieres G, van den Bergh H, Monnier P (2000) Photodynamic therapy of early squamous cell cancers of the esophagus. Gastrointest Endosc Clin N Am 10(3):439-460

2. van den Bergh H, Ballini JP (2003) Photodynamic therapy: basic principle. In: FFaK S (ed) Lasers in ophthalmology-basic, diagnostic and surgical aspects. Kugler Publications, The Hague, pp 183-195

3. Henderson BW, Dougherty TJ (1992) How does photodynamic therapy work? Photochem Photobiol 55(1):145-157

4. Hopper C (2000) Photodynamic therapy: a clinical reality in the treatment of cancer. Lancet Oncol 1:212-219

5. Star WM, Marijnissen HP, van den Berg-Blok AE, Versteeg JA, Franken KA, Reinhold HS (1986) Destruction of rat mammary tumor and normal tissue microcirculation by hematoporphyrin derivative photoradiation observed in vivo in sandwich observation chambers. Cancer Res 46(5):2532-2540

6. Henderson BW, Waldow SM, Mang TS, Potter WR, Malone PB, Dougherty TJ (1985) Tumor destruction and kinetics of tumor cell death in two experimental mouse tumors following photodynamic therapy. Cancer Res 45(2):572-576

7. Selman SH, Kreimer-Birnbaum M, Klaunig JE, Goldblatt PJ, Keck RW, Britton SL (1984) Blood flow in transplantable bladder tumors treated with hematoporphyrin derivative and light. Cancer Res 44(5):1924-1927

8. Reed MW, Schuschke DA, Miller FN (1991) Prostanoid antagonists inhibit the response of the microcirculation to "early" photodynamic therapy. Radiat Res 127(3):292-296

9. Chan WM, Lim TH, Pece A, Silva R, Yoshimura N (2010) Verteporfin PDT for non-standard indications-a review of current literature. Graefes Arch Clin Exp Ophthalmol 248(5):613-626

10. Hendrich C, Huttmann G, Vispo-Seara JL, Houserek S, Siebert WE (2000) Experimental photodynamic laser therapy for rheumatoid arthritis with a second generation photosensitizer. Knee Surg Sports Traumatol Arthrosc 8(3):190-194

11. Choudhary S, Nouri K, Elsaie ML (2009) Photodynamic therapy in dermatology: a review. Lasers Med Sci 24(6):971-980

12. O'Connor AE, Gallagher WM, Byrne AT (2009) Porphyrin and nonporphyrin photosensitizers in oncology: preclinical and clinical advances in photodynamic therapy. Photochem Photobiol 85(5):1053-1074

13. Ishiwata I, Ishiwata $C$, Soma $M$, Ono I, Nakaguchi $T$, Ishikawa $H$ (1988) Tumor angiogenic activity of gynecologic tumor cell lines on the chorioallantoic membrane. Gynecol Oncol 29(1):87-93

14. Debefve E, Pegaz B, Ballini JP, van den Bergh H (2009) Combination therapy using verteporfin and ranibizumab; optimizing the timing in the CAM model. Photochem Photobiol 85(6): 1400-1408

15. Debefve E, Pegaz B, van den Bergh H, Wagnieres G, Lange N, Ballini JP (2008) Video monitoring of neovessel occlusion induced by photodynamic therapy with verteporfin (Visudyne), in the CAM model. Angiogenesis 11(3):235-243

16. Pegaz B, Debefve E, Ballini JP, Wagnieres G, Spaniol S, Albrecht V et al (2006) Photothrombic activity of m-THPC-loaded liposomal formulations: pre-clinical assessment on chick chorioallantoic membrane model. Eur J Pharm Sci 28(1-2):134-140

17. Lim SH, Nowak-Sliwinska P, Kamarulzaman FA, van den Bergh H, Wagnieres G, Lee HB. (2010) The Neovessel Occlusion Efficacy of 15-Hydroxypurpurin-7-Lactone Dimethyl Ester Induced with Photodynamic Therapy. Photochem Photobiol

18. Hasan J, Shnyder SD, Bibby M, Double JA, Bicknel R, Jayson GC (2004) Quantitative angiogenesis assays in vivo-a review. Angiogenesis 7(1):1-16

19. Lobrinus JA, Juillerat-Jeanneret L, Darekar P, Schlosshauer B, Janzer RC (1992) Induction of the blood-brain barrier specific HT7 and neurothelin epitopes in endothelial cells of the chick chorioallantoic vessels by a soluble factor derived from astrocytes. Brain Res Dev Brain Res 70(2):207-211

20. Ribatti D, Nico B, Vacca A, Roncali L, Burri PH, Djonov V (2001) Chorioallantoic membrane capillary bed: a useful target for studying angiogenesis and anti-angiogenesis in vivo. Anat Rec 264(4):317-324 
21. Ferrario A, von Tiehl KF, Rucker N, Schwarz MA, Gill PS, Gomer CJ (2000) Antiangiogenic treatment enhances photodynamic therapy responsiveness in a mouse mammary carcinoma. Cancer Res 60(15):4066-4069

22. Ju M, Mailhos C, Bradley J, Dowie T, Ganley M, Cook G et al (2008) Simultaneous but not prior inhibition of VEGF165 enhances the efficacy of photodynamic therapy in multiple models of ocular neovascularization. Invest Ophthalmol Vis Sci 49(2):662-670

23. Zuluaga MF, Lange N (2008) Combination of photodynamic therapy with anti-cancer agents. Curr Med Chem 15(17):16551673

24. Petermeier K, Tatar O, Inhoffen W, Volker M, Lafaut BA, Henke-Fahle $S$ et al (2006) Verteporfin photodynamic therapy induced apoptosis in choroidal neovascular membranes. $\mathrm{Br} \mathrm{J}$ Ophthalmol 90(8):1034-1039

25. Lim SH, Thivierge C, Nowak-Sliwinska P, Han J, van den Bergh $\mathrm{H}$, Wagnieres $\mathrm{G}$ et al (2010) In vitro and in vivo photocytotoxicity of boron dipyrromethene derivatives for photodynamic therapy. J Med Chem 53(7):2865-2874

26. Nowak-Sliwinska P, Karocki A, Elas M, Pawlak A, Stochel G, Urbanska K (2006) Verteporfin, photofrin II, and merocyanine 540 as PDT photosensitizers against melanoma cells. Biochem Biophys Res Commun 349(2):549-555

27. Schmidt-Erfurth U, Schlotzer-Schrehard U, Cursiefen C, Michels S, Beckendorf A, Naumann GO (2003) Influence of photodynamic therapy on expression of vascular endothelial growth factor (VEGF), VEGF receptor 3, and pigment epithelium-derived factor. Invest Ophthalmol Vis Sci 44(10): 4473-4480

28. Beckstead JH (1995) A simple technique for preservation of fixation-sensitive antigens in paraffin-embedded tissues: addendum. J Histochem Cytochem 43(3):345

29. Pfaffl MW (2001) A new mathematical model for relative quantification in real-time RT-PCR. Nucleic Acids Res 29(9):e45

30. Nowak-Sliwinska P, Ballini JP, Wagnieres G, van den Bergh H (2010) Processing of fluorescence angiograms for the quantification of vascular effects induced by anti-angiogenic agents in the CAM model. Microvasc Res 79(1):21-28

31. van Beijnum JR, Dings RP, van der Linden E, Zwaans BM, Ramaekers FC, Mayo KH et al (2006) Gene expression of tumor angiogenesis dissected: specific targeting of colon cancer angiogenic vasculature. Blood 108(7):2339-2348

32. Thijssen VL, Postel R, Brandwijk RJ, Dings RP, Nesmelova I, Satijn S et al (2006) Galectin-1 is essential in tumor angiogenesis and is a target for antiangiogenesis therapy. Proc Natl Acad Sci USA 103(43):15975-15980

33. Griffioen AW, Damen CA, Martinotti S, Blijham GH, Groenewegen G (1996) Endothelial intercellular adhesion molecule-1 expression is suppressed in human malignancies: the role of angiogenic factors. Cancer Res 56(5):1111-1117

34. Pegaz B, Debefve E, Ballini JP, Konan-Kouakou YN, van den Bergh H (2006) Effect of nanoparticle size on the extravasation and the photothrombic activity of meso(p-tetracarboxyphenyl)porphyrin. J Photochem Photobiol B 85(3):216-222

35. Pegaz B, Debefve E, Borle F, Ballini JP, van den Bergh H, Kouakou-Konan YN (2005) Encapsulation of porphyrins and chlorins in biodegradable nanoparticles: the effect of dye lipophilicity on the extravasation and the photothrombic activity. A comparative study. J Photochem Photobiol B 80(1):19-27

36. Pegaz B, Debefve E, Borle F, Ballini JP, Wagnieres G, Spaniol S et al (2005) Preclinical evaluation of a novel water-soluble chlorin E6 derivative (BLC 1010) as photosensitizer for the closure of the neovessels. Photochem Photobiol 81(6):1505-1510

37. Biel MA (2007) Photodynamic therapy treatment of early oral and laryngeal cancers. Photochem Photobiol 83(5):1063-1068
38. Grosjean P, Wagnieres G, Fontolliet C, van den Bergh H, Monnier P (1998) Clinical photodynamic therapy for superficial cancer in the oesophagus and the bronchi: $514 \mathrm{~nm}$ compared with $630 \mathrm{~nm}$ light irradiation after sensitization with Photofrin II. Br J Cancer 77(11):1989-1995

39. Arroyo JG, Michaud N, Jakobiec FA (2003) Choroidal neovascular membranes treated with photodynamic therapy. Arch Ophthalmol 121(6):898-903

40. Yuan F, Chen Y, Dellian M, Safabakhsh N, Ferrara N, Jain RK (1996) Time-dependent vascular regression and permeability changes in established human tumor xenografts induced by an anti-vascular endothelial growth factor/vascular permeability factor antibody. Proc Natl Acad Sci USA 93(25):14765-14770

41. Gerhardt H, Golding M, Fruttiger M, Ruhrberg C, Lundkvist A, Abramsson A et al (2003) VEGF guides angiogenic sprouting utilizing endothelial tip cell filopodia. J Cell Biol 161(6): 1163-1177

42. Flamme I, von Reutern M, Drexler HC, Syed-Ali S, Risau W (1995) Overexpression of vascular endothelial growth factor in the avian embryo induces hypervascularization and increased vascular permeability without alterations of embryonic pattern formation. Dev Biol 171(2):399-414

43. Zuluaga MF, Mailhos C, Robinson G, Shima DT, Gurny R, Lange N (2007) Synergies of VEGF inhibition and photodynamic therapy in the treatment of age-related macular degeneration. Invest Ophthalmol Vis Sci 48(4):1767-1772

44. Ley CD, Olsen MW, Lund EL, Kristjansen PE (2004) Angiogenic synergy of bFGF and VEGF is antagonized by Angiopoietin- 2 in a modified in vivo Matrigel assay. Microvasc Res 68(3):161-168

45. Schmidt-Erfurth U, Hasan T (2000) Mechanisms of action of photodynamic therapy with verteporfin for the treatment of agerelated macular degeneration. Surv Ophthalmol 45(3):195-214

46. Tatar O, Adam A, Shinoda K, Stalmans P, Eckardt C, Luke M et al (2006) Expression of VEGF and PEDF in choroidal neovascular membranes following verteporfin photodynamic therapy. Am J Ophthalmol 142(1):95-104

47. Uehara M, Inokuchi T, Sano K, Zuo Lin W (2001) Expression of vascular endothelial growth factor in mouse tumours subjected to photodynamic therapy. Eur J Cancer 37(16):2111-2115

48. Togashi H, Uehara M, Ikeda H, Inokuchi T (2006) Fractionated photodynamic therapy for a human oral squamous cell carcinoma xenograft. Oral Oncol 42(5):526-532

49. Chang SK, Rizvi I, Solban N, Hasan T (2008) In vivo optical molecular imaging of vascular endothelial growth factor for monitoring cancer treatment. Clin Cancer Res 14(13):4146-4153

50. Bhuvaneswari R, Thong PS, Gan YY, Soo K, Olivo M (2010) Evaluation of hypericin-mediated photodynamic therapy in combination with angiogenesis inhibitor bevacizumab using in vivo fluorescence confocal endomicroscopy. J Biomed Opt 15(1):011114

51. Brooks PC, Montgomery AM, Rosenfeld M, Reisfeld RA, Hu T, Klier $\mathrm{G}$ et al (1994) Integrin alpha $\mathrm{v}$ beta 3 antagonists promote tumor regression by inducing apoptosis of angiogenic blood vessels. Cell 79(7):1157-1164

52. Prasad SC, Thraves PJ, Kuettel MR, Srinivasarao GY, Dritschilo A, Soldatenkov VA (1998) Apoptosis-associated proteolysis of vimentin in human prostate epithelial tumor cells. Biochem Biophys Res Commun 249(2):332-338

53. Belichenko I, Morishima N, Separovic D (2001) Caspase-resistant vimentin suppresses apoptosis after photodynamic treatment with a silicon phthalocyanine in Jurkat cells. Arch Biochem Biophys 390(1):57-63

54. Nowak-Sliwinska P, Wagnieres G, van den Bergh H, Griffioen AW (2010) Angiostasis-induced vascular normalization can improve photodynamic therapy. Cell Mol Life Sci 67(9):1559-1560 